\title{
BMJ Open Effect of interventions based on educational technologies on the prevention of sexually transmitted infections in incarcerated women: protocol of a systematic review and meta-analysis
}

Isaiane da Silva Carvalho (D) ," Ryanne Carolynne Marques Gomes Mendes (D) , Priscila de Oliveira Cabral Melo (D) , ${ }^{1}$ Caroline Ferraz Simões (D) ,2 Luciana Pedrosa Leal (D) ,' Tatiane Gomes Guedes (D) ,' Gabriela Isabel Reyes Ormeno, ${ }^{3}$ Francisca Márcia Pereira Linhares (D) ${ }^{1}$

To cite: Carvalho IdS, Mendes RCMG, Melo PdOC, et al. Effect of interventions based on educational technologies on the prevention of sexually transmitted infections in incarcerated women: protocol of a systematic review and meta-analysis. BMJ Open 2021;11:e043373. doi:10.1136/ bmjopen-2020-043373

- Prepublication history and additional supplemental material for this paper are available online. To view these files, please visit the journal online (http://dx.doi.org/10.1136/ bmjopen-2020-043373).

Received 02 August 2020 Revised 22 December 2020 Accepted 04 March 2021

Check for updates

(C) Author(s) (or their employer(s)) 2021. Re-use permitted under CC BY-NC. No commercial re-use. See rights and permissions. Published by BMJ.

For numbered affiliations see end of article.

Correspondence to Dr Isaiane da Silva Carvalho; isaianekarvalho@hotmail.com

\section{ABSTRACT}

Introduction Prisons are places with high vulnerability and high risk for the development of sexually transmitted infections. World Health Agencies recommend establishing intervention measures, such as information and education, on the prevention of diseases. Thus, technologies as tools for health education have been used to reduce sexually transmitted infections. However, no systematic review has investigated the effectiveness of these interventions. Therefore, this review's objective is to examine the effect of educational technologies used for preventing sexually transmitted infections in incarcerated women.

Methods and analysis Preferred Reporting Items for Systematic Reviews and Meta-Analyses guidelines will be strictly followed. The following electronic databases will be searched: Scopus; Cumulative Index of Nursing and Allied Health, Education Resources Information Center, Embase, PsycINF0, PubMed/Medline, Web of Science and Google Scholar. Randomised clinical trials of interventions that used educational technologies to prevent sexually transmitted infections in incarcerated women will be searched in the databases from the beginning of 2020 until December by two researchers independently. A narrative synthesis will be constructed for all included studies, and if there are sufficient data, a meta-analysis will be performed using the Review Manager software (V.5.3). Continuous results will be presented as the weighted mean difference or the standardised mean difference with $95 \% \mathrm{Cls}$. Under the heterogeneity of the included studies, a random-effects or fixed-effects model will be used. The studies' heterogeneity will be assessed by the $I^{2}$ method. The sensitivity analysis will be carried out to examine the magnitude of each study's influence on the general results. A significance level of $\mathrm{p} \leq 0.05$ will be adopted.
Strengths and limitations of this study

This systematic review and meta-analysis will combine results from different studies that have comparable effect sizes.

- The protocol of systematic reviews presents a robust methodology that can serve as a basis for other researchers.

- The study screening, data extraction and quality assessment will be performed by two independent reviewers and a third researcher as an arbitrator.

- Different types of technologies may be identified and cause considerable heterogeneity, influencing clear conclusions.

- The analyses are carried out based on group data and not on the individual data of the participants.

Ethics and disclosure Ethical approval is not required because no primary data will be collected. The results will be published in journals reviewed by peers.

PROSPERO registration number CRD42020163820.

\section{INTRODUCTION}

There are about 714000 incarcerated women globally, and these numbers may be higher due to the lack of record or under-reporting of data present in some countries. This number corresponds to $6.9 \%$ of the prison population worldwide, and the countries with the highest number of incarcerated women are the USA (200 000), followed by China (107 131), Russia (48 478), Brazil (approximately 44700 ) and Thailand (41 119). Furthermore, in the year 2000 , this population increased by about $53 \%$, the world population by $21 \%$, and the male prison population by $20 \%{ }^{1}$ 
Due to their structure, prisons are places with high vulnerability and high risk for the development of sexually transmitted infections (STIs). ${ }^{2}$ Such infections can be caused by more than 30 different aetiological agents, and their main route of transmission is sexual contact. Some of these infections have high prevalence rates and are more severe in women because when not detected in time, they can cause, for example, congenital syphilis, pelvic inflammatory disease, infertility and cervical cancer. Besides, there are stigma, discrimination and prejudice resulting from STI's cultural, psychological and biological aspects. ${ }^{3}$ Among the researches on STI in incarcerated women, there stands out the association with HIV, syphilis, genital herpes, viral hepatitis, gonorrhoea, chlamydia and human papilloma virus. ${ }^{4-11}$

Moreover, it is crucial to consider that the high number of incarcerated people, coupled with the high turnover present in prison systems and the considerable number of prisoners who will return to the community, makes STI a severe public health problem. ${ }^{12}$ In the face of this problem, the WHO proposes comprehensive intervention measures on STI as a strategy for these spaces. ${ }^{2}$ Equally, the Bangkok Rules, which discuss the treatment provided to incarcerated women and non-custodial measures for women offenders, report the need to provide information and education on how to prevent STI in prison spaces. These rules were defined to have a global scope concerning these women's particularities. They were developed based on other resolutions adopted by the United Nations, in line with current international law. ${ }^{13}$

Thus, technologies as tools for health education can improve teaching quality through a pedagogical approach considering creativity and interactivity between educator and learner. ${ }^{14}$ Furthermore, they can represent one more tool to be considered in preventing STIs in prisons. The educational technologies used for this purpose can be of different types, such as printed materials (cards, pictures, folders e-booklets), games, videos and simulators. ${ }^{15}$ In this way, the technologies described here go beyond the universe of digital equipment.

Different technologies can be used in the teaching process of STI, including prisons. ${ }^{16-18}$ However, no systematic review was found as the International Prospective Registry of Systematic Reviews (PROSPERO) and Cochrane Database of Systematic Reviews did not have systematic review/meta-analysis records on the subject. Thus, this systematic review with meta-analysis aims to examine the effect of interventions based on educational technologies in the prevention of STIs in incarcerated women.

\section{METHODS}

The protocol was developed according to the Preferred Reporting Items for Systematic Review and Meta-Analysis Protocols ${ }^{19}$ and the Cochrane Handbook guidelines for Systematic Reviews of Interventions. ${ }^{20}$ The protocol was registered with the PROSPERO.

\section{Study eligibility}

Characteristics of the studies

The literature search will include studies according to the review's pre-established criteria, objectives, participants, interventions, comparisons and outcomes (PICO). Randomised clinical trials (RCTs) or cluster-RCT primary studies of interventions that used educational technologies in the prevention of STIs in incarcerated women will be selected according to the recommendations of the Cochrane Effective Practice and Organization of Care (EPOC), ${ }^{21}$ without language restriction, published until 31 December 2020.

\section{Participants}

Studies with incarcerated women, regardless of age, race, nationality and education level, developed in the prison environment, who have received some intervention using educational technologies related to STI, will be considered. Studies in which it is not possible to identify an educational technology will be excluded.

\section{Interventions}

Studies evaluating the effect of educational technologies as an independent or combined intervention (association with expository or dialogued expository lecture, for example) will be considered interventions. This systematic review will adopt the concept of educational technology as 'the ethical study and practice to facilitate learning and improve performance, creating, using, and managing appropriate technological processes and resources'. ${ }^{22}$

\section{Comparators}

Studies whose control group received any educational intervention without a preventive focus on STI or no educational intervention will be considered comparators.

\section{Outcome measures}

Studies reporting the effect of educational technologies related to sexual risk (reduced number of episodes of unprotected sex or sexual partners or correct use of a condom) in incarcerated women will be considered the outcome measures. According to the concept of educational technologies described above, educational technologies will include digital and non-digital technologies, which involve, for example, printed materials, games, videos and simulators. ${ }^{15}$ Secondary outcomes will include knowledge about STI and incidence of STI.

\section{Information sources}

The systematic search will comprise eight electronic databases: Scopus; Cumulative Index of Nursing and Allied Health; Education Resources Information Center; Embase; PsycINFO; PubMed/Medline; Web of Science and Google Scholar. Additionally, a manual search of the list of references of eligible articles will also be carried out to identify any potentially relevant study. The EndNote bibliographical software will be used to manage all references to ensure a comprehensive survey. 


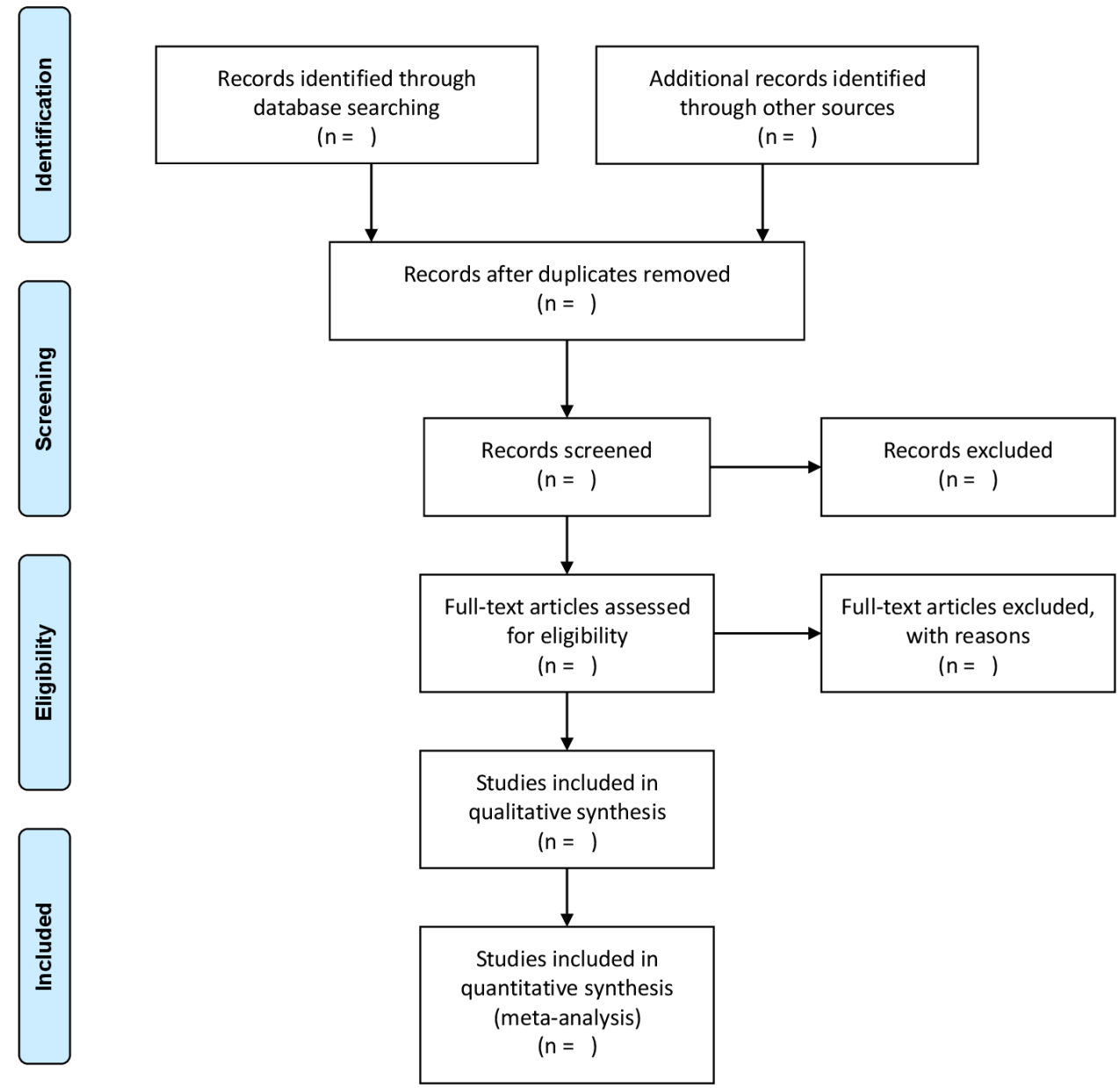

Figure 1 Preferred Reporting Items for Systematic Reviews and Meta-Analyses (PRISMA) flow chart. Source: PRISMA flow diagram. ${ }^{24}$

The $\mathrm{PICO}^{23}$ strategy was used to formulate the research question: 'What is the effect of interventions based on educational technologies on STI prevention in incarcerated women?' Initially, controlled Medical Subject Headings terms, and their synonyms were selected. The terms were combined using the Boolean operators "AND" and "OR". The search strategy was developed at PubMed and subsequently will be adapted for other databases (online supplemental appendix 1).

\section{Selection of studies}

Two researchers will independently select scientific articles through the title and abstract's initial reading, based on the eligibility criteria mentioned above. Subsequently, the articles will be fully read. All differences arising at any step in the selection and analysis process will be solved through consensus between the researchers. In case of no agreement, a third researcher will be contacted to establish a final decision. The reasons for excluding some articles will be presented in a Preferred Reporting Items for Systematic Reviews and Meta-Analyses flow chart (figure 1). ${ }^{24}$

Data extraction will be performed by two researchers with the aid of a specific form ${ }^{25}$ and will also consider the data extraction form for primary studies proposed by the
EPOC. ${ }^{26}$ The items that will be collected are described below. As the review will assess the effect of educational interventions on sexual risk, the details of the interventions will be selected to establish the studies' reproducibility. ${ }^{27}$ Essential data for the risk of bias assessment (allocation and blinding) will also be extracted. The data will be inserted in the RevMan software (V.5.3.5), ${ }^{28}$ which allows for managing and analysing data during a systematic review.

The following items will be extracted from the selected articles: authors; year of publication; country of study; objective; research project; settings; characteristics of the participants (age and ethnicity); health; sampling method; sample size; number and percentage of participants; research method/data collection tool; intervention (type of technology); control (alternative intervention/placebo/conventional care); total duration of the intervention (weeks/months); stages of measurement-baseline, follow-up 1, 2, 3 (weeks/ months after the baseline); outcome/discoveries (including mean values, SD and CIs); conclusion of the authors; quality of the study (evaluation of the reviewers / comments on the study)..$^{25} 26$ 


\section{Risk of bias in individual studies}

Two researchers will assess the risk of bias based on the criteria proposed by the EPOC, ${ }^{29}$ which includes nine criteria whose outcome may be the following options: low risk, high risk and unclear risk of bias. The criteria are the generation of random sequence; allocation concealment; blinding of participants and personnel; blinding of outcome assessment; incomplete outcome data; selective outcome reporting; and other risks of bias.

The publication bias will be evaluated and classified according to the number of studies included in the metaanalysis: number of studies bigger or equal to 10-funnel chart in RevMan (V.5.3). ${ }^{28}$ The interpretation will occur based on the Cochrane Handbook for Systematic Reviews of Interventions. ${ }^{20}$

\section{Data synthesis}

The RevMan (V.5.3) software will be used for the metaanalysis. ${ }^{28}$ The meta-analysis will assess the effect ofinterventions based on educational technologies in the prevention of STI. It will be composed only of studies with a low risk of bias, according to the EPOC. ${ }^{29}$ In case of no article with a low risk of bias, the meta-analysis will not be developed. Continuous results will be presented as the weighted mean difference (MD) or the standardised MD with $95 \%$ CIs. Under the heterogeneity of the included studies, a random-effects or fixed-effects model will be used. The heterogeneity between the studies will be measured by the Cochran $\mathrm{Q}$ and $\mathrm{I}^{2}$ tests. ${ }^{30}$ A significance level of $p \leq 0.05$ will be adopted.

The size of each study's primary effect will be calculated from the first stage of measurement after implementing the intervention. For studies with more than one intervention group, the primary effect size will be measured for the group presenting the intervention's main characteristics or a smaller number of methodological flaws. In turn, for studies with more than one control group, the primary effect will be calculated for the group presenting the highest expected difference concerning the intervention group. ${ }^{30}$

\section{Subgroup analysis}

If there are enough studies, we will conduct a subgroup analysis based on the different educational technologies used to prevent STIs in incarcerated women.

\section{Sensitivity analysis}

A sensitivity analysis will be conducted to examine the magnitude of each study's influence on the general results of the comparisons.

\section{Quality of evidence assessment}

The quality of evidence will be assessed through the Grading of Recommendations Assessment, Development and Evaluation approach. Each outcome can be classified according to the following levels of evidence: very low, low, moderate and high. These results represent the level of confidence in the estimated effect. The quality of evidence includes methodological limitations (risk of bias), inconsistency, indirect evidence, inaccuracy and publication bias. Two independent researchers will conduct this quality assessment. ${ }^{31}$

\section{Qualitative data synthesis}

Additionally, a qualitative data synthesis will be presented, even if the meta-analysis is not performed, including a description of aspects such as year of publication, country of origin, sample size, type of intervention and outcomes. A chart will also be presented with a general summary of the educational technologies evaluated.

\section{Ethics and dissemination}

This study is a protocol whose goal is to perform a systematic review and meta-analysis of studies previously published. Thus, there was no human recruitment, and the analyses will not occur concerning the individual participants. Therefore, there is no need for approval from a research ethics committee. The results of this study will be published in journals reviewed by peers.

\section{Patient and public involvement}

No patient involved.

\section{Author affiliations}

${ }^{1}$ Nursing Postgraduate Program, Federal University of Pernambuco, Recife, Brazil ${ }^{2}$ Physical Education Postgraduate Program, State University of Maringá, Maringa, Brazil

${ }^{3}$ Department of Education, Federal University of Parana, Curitiba, Brazil

Acknowledgements This research will be performed as part of the doctorate studies of the first author in the context of the Nursing Postgraduate Program of the Federal University of Pernambuco, Recife, Brazil.

Contributors IdSC-definition of PICO question, writing the protocol and the present manuscript and coordination of the protocol development. RCMGMoutcome definition and review of protocol and manuscript. PdOCM—outcome definition and review of protocol and manuscript. CFS-outcome definition and review of protocol and manuscript. LPL—definition of PICO question, outcome definition and review of protocol and manuscript. TGG — outcome definition and review of protocol and manuscript. GIRO-definition of PICO question, outcome definition and review of protocol and manuscript. FMPL-definition of PICO question, outcome definition and review of protocol and manuscript, and coordination of the protocol development.

Funding This study was financed in part by the Coordenação de Aperfeiçoamento de Pessoal de Nível Superior - Brasil (CAPES) - Finance Code 001

Competing interests None declared.

Patient consent for publication Not required.

Provenance and peer review Not commissioned; externally peer reviewed.

Supplemental material This content has been supplied by the author(s). It has not been vetted by BMJ Publishing Group Limited (BMJ) and may not have been peer-reviewed. Any opinions or recommendations discussed are solely those of the author(s) and are not endorsed by BMJ. BMJ disclaims all liability and responsibility arising from any reliance placed on the content. Where the content includes any translated material, BMJ does not warrant the accuracy and reliability of the translations (including but not limited to local regulations, clinical guidelines, terminology, drug names and drug dosages), and is not responsible for any error and/or omissions arising from translation and adaptation or otherwise.

Open access This is an open access article distributed in accordance with the Creative Commons Attribution Non Commercial (CC BY-NC 4.0) license, which permits others to distribute, remix, adapt, build upon this work non-commercially, and license their derivative works on different terms, provided the original work is properly cited, appropriate credit is given, any changes made indicated, and the use is non-commercial. See: http://creativecommons.org/licenses/by-nc/4.0/. 


\section{ORCID iDs}

Isaiane da Silva Carvalho http://orcid.org/0000-0002-8478-2032

Ryanne Carolynne Marques Gomes Mendes http://orcid.org/0000-0001-7554-2662

Priscila de Oliveira Cabral Melo http://orcid.org/0000-0002-6105-2248

Caroline Ferraz Simões http://orcid.org/0000-0003-0391-234X

Luciana Pedrosa Leal http://orcid.org/0000-0003-3776-0997

Tatiane Gomes Guedes http://orcid.org/0000-0001-7149-2290

Francisca Márcia Pereira Linhares http://orcid.org/0000-0001-9778-5024

\section{REFERENCES}

1 Institute for Criminal Policy Research (ICPR). World female imprisonment list. 4 ed. London: ICPR, 2017.

2 World Health Organization. Global health sector strategy on sexually transmitted infections, 2016-2021. Geneva: WHO, 2016.

3 Ministério da Saúde (BR). Protocolo clínico e diretrizes terapêuticas para atenção integral s pessoas com infecções sexualmente transmissíveis. Brasília: Ministério da Saúde, 2015.

4 Adams JW, Lurie MN, King MRF, et al. Potential drivers of HIV acquisition in African-American women related to mass incarceration: an agent-based modelling study. BMC Public Health 2018;18:1387-97.

5 Villarroel-Torrico M, Montaño K, Flores-Arispe P, et al. Syphilis, human immunodeficiency virus, herpes genital and hepatitis $B$ in a women's prison in Cochabamba, Bolivia: prevalence and risk factors. Rev Esp Sanid Penit 2018;20:47-54.

6 Domingues RMSM, Leal MdoC, Pereira APE, et al. Prevalence of syphilis and HIV infection during pregnancy in incarcerated women and the incidence of congenital syphilis in births in prison in Brazil. Cad Saude Publica 2017;33:e00183616.

7 DiClemente RJ, Davis TL, Swartzendruber A, et al. Efficacy of an HIV/STI sexual risk-reduction intervention for African American adolescent girls in juvenile detention centers: a randomized controlled trial. Women Health 2014;54:726-49.

8 Satterwhite CL, Newman D, Collins D, et al. Chlamydia screening and positivity in juvenile detention centers, United States, 20092011. Women Health 2014;54:712-25.

9 Cole J, Hotton A, Zawitz C, et al. Opt-out screening for Chlamydia trachomatis and Neisseria gonorrhoeae in female detainees at Cook County jail in Chicago, IL. Sex Transm Dis 2014;41:161-5.

10 Barros LAS, Pessoni GC, Teles SA, et al. Epidemiology of the viral hepatitis $B$ and $C$ in female prisoners of metropolitan regional prison complex in the state of Goiás, central Brazil. Rev Soc Bras Med Trop 2013;46:24-9.

11 Zonta MA, Monteiro J, Jr S. Oral infection by the human papilloma virus in women with cervical lesions at a prison in São Paulo, Brazil. Braz J Otorrinolaringol 2012;78:66-72.

12 Nijhawan AE. Infectious diseases and the criminal justice system: a public health perspective. Am J Med Sci 2016;352:399-407.

13 United Nations Office on Drugs and Crime (UNODC). The Bangkok rules 2015, 2011. Available: https://www.unodc.org/documents/ justice-and-prison-reform/Bangkok_Rules_ENG_22032015.pdf
14 Salvador P, Rodrigues C, Lima KY. Uso E desenvolvimento de tecnologias para $\mathrm{O}$ ensino apresentados em pesquisas de enfermagem. Rev Rene 2015;16:442-50.

15 Carvalho IdaS, Guedes TG, Bezerra SMMdaS, Bezerra S, et al. Educational technologies on sexually transmitted infections for incarcerated women. Rev Lat Am Enfermagem 2020;28:e3392.

16 Guedes TG, Linhares FMP, Morais SCRV, et al. Health education: strategy for sexual and reproductive care for women in custody. Procedia Soc Behav Sci 2015;174:821-5.

17 Johnson JE, Peabody ME, Wechsberg WM, et al. Feasibility of an HIV/STI Risk-Reduction program for incarcerated women who have experienced interpersonal violence. J Interpers Violence 2015;30:3244-66.

18 Gupta N, Schmidt H, Buisker T, et al. After the fact: a brief educational program on HIV postexposure prophylaxis for female detainees in a local jail. J Correct Health Care 2015;21:140-51.

19 Shamseer L, Moher D, Clarke M, et al. Preferred reporting items for systematic review and meta-analysis protocols (PRISMA-P) 2015: elaboration and explanation. BMJ 2015;349:g7647.

20 The Cochrane Collaboration. Cochrane Handbook for systematic reviews of interventions version 5.1.0. London: The Cochrane Collaboration, 2011.

21 Cochrane Effective Practice and Organisation of Care Review Group (EPOC). What study designs should be included in an EPOC review and what should they be called? 2014. Available: http://epoc. cochrane.org/sites/epoc.cochrane.org/files/public/uploads/EPOC\% 20Study\%20Designs\%20About.pdf

22 Januszewski A, Molenda M. Educational technology: a definition with commentary. Nova York: Routledge, 2008.

23 Pollock A, Berge E. How to do a systematic review. Int J Stroke 2018;13:138-56.

24 Liberati A, Altman DG, Tetzlaff J, et al. The PRISMA statement for reporting systematic reviews and meta-analyses of studies that evaluate health care interventions: explanation and elaboration. PLoS Med 2009;6:e1000100.

25 Shah SGS, Nogueras D, van Woerden H, et al. Effectiveness of digital technology interventions to reduce loneliness in adults: a protocol for a systematic review and meta-analysis. BMJ Open 2019;9:e032455.

26 Cochrane Effective Practice and Organisation of Care Review Group (EPOC). Data collection checklist. Ottawa, Canada: Institute of Population Health, University of Ottawa, 2002.

27 Munn Z, Tufanaru C, Aromataris E. JBI's systematic reviews: data extraction and synthesis. Am J Nurs 2014;114:49-54.

28 The Cochrane Collaboration. RevMan5, 2017. Available: http:// community.cochrane.org/tools/review-production-tools/revman-5

29 Cochrane Effective Practice and Organisation of Care (EPOC). Suggested risk of bias criteria for EPOC reviews, 2017. Available: http://epoc.cochrane.org/epoc-specific-resources-review-authors

30 Masi CM, Chen H-Y, Hawkley LC, et al. A meta-analysis of interventions to reduce loneliness. Pers Soc Psychol Rev 2011;15:219-66.

31 Dijkers M. Introducing grade: a systematic approach to rating evidence in systematic reviews and Guideline development. KT Update 2013;1:1-9. 